\title{
Study of extra-articular manifestations and disease severity in patients with rheumatoid arthritis
}

\author{
Mahendrakumar Kalappan ${ }^{1}$, Naufal Rizwan Taraganar Abubacker ${ }^{1}$, Meenakshi Shetty ${ }^{2}$, \\ Kannan Rajendran ${ }^{1}$, Warun Kumar Muthupillai Rathinam ${ }^{1}$, Rajendran Karuthodiyil ${ }^{1}$
}

\author{
${ }^{1}$ Department of General Medicine, Saveetha Medical College Hospital, Chennai, Tamilnadu, India \\ ${ }^{2}$ Department of General Medicine, Kasturba Medical College Hospital, Mangalore, Karnataka, India
}

Received: 03 January 2016

Accepted: 22 January 2016

\section{*Correspondence:}

Dr. Mahendrakumar Kalappan,

E-mail: mahindran1985@gmail.com

Copyright: ( $)$ the author(s), publisher and licensee Medip Academy. This is an open-access article distributed under the terms of the Creative Commons Attribution Non-Commercial License, which permits unrestricted non-commercial use, distribution, and reproduction in any medium, provided the original work is properly cited.

\begin{abstract}
Background: The prevalence of chronic diseases in modern industrialized nations is increasing and among these intractable conditions, rheumatoid arthritis (RA) stands out as a major cause of multiple medical problems. Rheumatoid arthritis is an inflammation of synovial tissue and is characterized by symmetric involvement of peripheral joints, with hands, feet and wrists being most commonly affected. RA also presents with systemic disturbances and extra-articular manifestations. The prevalence of RA is reported to be $0.5-1 \%$ in the population worldwide, affecting women more frequently than men. One study carried out in India reported a figure of $0.5 \%$. Although considered a "joint disease", rheumatoid arthritis is also associated with extra-articular manifestations. Prevalence of these manifestations is seen in about $40 \%$ of patients at any time during the course of the disease. The objective was to study extra-articular manifestations and disease severity in patients with rheumatoid arthritis.

Methods: A Cross sectional study carried out among RA patients in inpatients and outpatients of tertiary care hospital. Based on the criteria, patients were selected and clinical history and examination was done. Locomotor system was examined and the total number of swollen and tender joints were counted and patient's perception of pain was analysed using visual analogue scale $(0-100 \mathrm{~mm})$ and disease severity was calculated using disease activity score 28 (DAS 28 score ).

Results: The results showed the mean age of rheumatoid arthritis to be 52.61 years, with the minimum age being 20 years and the maximum age being 81 years. Among 100 patients, $84 \%$ were females and $16 \%$ were males. Among 100 patients, $27 \%$ of patients had extra articular manifestations. The most common extra articular manifestation seen in the study was interstitial lung disease, a pulmonary manifestation, which was present in $11 \%$ of patients. There was a statistical significance between the association of extra-articular manifestation and disease severity.

Conclusions: Extra articular manifestations was seen in $27 \%$ of patients, most common was interstitial lung disease, indicating more extensive investigative protocol warranted for diagnosing milder presentation of these serious manifestations.
\end{abstract}

Keywords: Rheumatoid arthritis, Extra-articular manifestations of rheumatoid arthritis, Disease activity score 28

\section{INTRODUCTION}

The prevalence of chronic diseases in modern industrialized nations is increasing and among these intractable conditions, rheumatoid arthritis (RA) stands out as a major cause of multiple medical problems. ${ }^{1}$
Rheumatoid arthritis is a chronic inflammatory disease of synovial joints of unknown etiology and is typically characterized by symmetrical, destructive and deforming polyarthritis of small and large joints with systemic disturbances and extra-articular manifestations. ${ }^{2}$ 
Rheumatoid arthritis is an autoimmune disorder with a worldwide prevalence of $1-2 \%$ women affected two to three times more commonly than men. ${ }^{3}$ One study carried out in India reported figure of $0.5 \%$. The main risk factors for the disease include genetic susceptibility, sex and age, smoking, infectious agents, hormonal, dietary, socioeconomic, and ethnic factors. Most of these factors are likely to be associated with both disease occurrence and severity. There is a definite familial tendency and a female dominance. The mean age at onset is 35-50 years.

RA is a potentially disabling disease and runs an unpredictable course. RA can be classified as early RA (< 24 months), established RA (24 - 60 months) and late RA (> 5 years). There is evidence that disability develops very early in the course of RA, and that the disease may be more amenable to treatment at an early stage. ${ }^{5}$

There is a 'window of opportunity' early in the course of RA, during which period; bulk of disease is caused by medically treatable active inflammation. Effective treatment during this phase gives the best opportunity to improve short term and long term clinical, radiological and functional outcomes. ${ }^{6}$

The American College of Rheumatology Subcommittee on Rheumatoid Arthritis Guidelines (ACRSRA) recommends that patients with suspected rheumatoid arthritis be referred within three months of presentation for confirmation of diagnosis and initiation of treatment with disease-modifying anti-rheumatic drugs (DMARDs). ${ }^{7}$

Predictors of poor outcomes in the early stages of rheumatoid arthritis include a relatively low functional score early in the disease progression, lower socioeconomic status, lower education level, strong family history of the disease, and early involvement of many joints. Prognosis is worse in patients who have a high ESR or CRP level at disease onset, positive rheumatoid factor, or early radiologic changes.

This study focuses on extra-articular manifestations and assessing the disease severity of rheumatoid arthritis and correlation of both, thereby taking adequate steps in detecting the extra articular manifestation in patients with severe rheumatoid arthritis.

\section{METHODS}

Ethics committee approval was obtained before the start of the study from the Institutional Ethics Committee. Study was done among RA patients in inpatients and outpatients of tertiary care hospital. We included patients with age $>16$ years and fulfilling ACR criteria for rheumatoid arthritis . ${ }^{8}$ Age at onset $\leq 16$ years, Arthritis of $<6$ weeks duration, seronegative spondyloarthritis, Overlap syndromes were excluded from the study. 100 patients were selected. Sampling method is based on nonrandom convenient sampling method. Based on the criteria patients are selected and clinical history and examination was done. Locomotor examination was done and total number of swollen and tender joints were counted and patient's perception of pain was analyzed using visual analog scale $(0-100 \mathrm{~mm})$ and disease severity was calculated using disease activity score 28 (DAS 28 score ). ${ }^{9}$

DAS28 $=0.56 \times \sqrt{ }($ tender 28$)+0.28 \times \sqrt{ }($ swollen28) + $0.70 \times \ln (\mathrm{ESR})+0.014 \times \mathrm{VAS}$

Disease activity was calculated by DAS 28 score $^{9}$ and the patient was classified as mild, moderate and severe

DAS 28 score <3.2 Mild

DAS 28 score $=3.2-5.1$ Moderate

DAS 28 score $>5.1$ Severe

The patients with rheumatoid arthritis without joint manifestations, initially presenting with extra articular manifestation and burnt out disease were classified as not applicable.

The data was collected and descriptive analysis of the data was done using Excel spread sheets and data analysis was done using SPSS version 17 data analyzer. Fisher's exact test was used to find the association between DAS 28 score and other factors.

\section{RESULTS}

The baseline characteristics of the study participants are described in Table 1.

Mean age of rheumatoid arthritis among study group was 52.61 yrs., minimum age of 20 and maximum age of $81 \mathrm{yrs}$ was observed. No statistical significance between the association of age and disease severity was observed (Table 2).

Among 100 patients $84 \%$ were females and $16 \%$ were males. No statistical significance was observed between association of sex and disease severity (Table 3 ).

Table 1: Baseline characteristics of the study participants.

\begin{tabular}{|c|c|c|c|}
\hline & Mean & SD & $95 \% \mathrm{CI}$ \\
\hline Age (years) & 52.61 & 14.45 & $49.74-55.48$ \\
\hline Male / Female & $16 / 84$ & & \\
\hline RA Factor positivity & $72 \%$ & & \\
\hline Duration (years) & 5.85 & 5.675 & $4.73-6.98$ \\
\hline EMS $^{\text {a }}$ (hours) & 2.01 & 0.93 & $1.83-2.19$ \\
\hline Tender joints & 10.84 & 5.89 & $9.66-12.01$ \\
\hline Swollen Joints & 5.14 & 4.27 & $4.29-5.99$ \\
\hline $\operatorname{VAS}^{\mathrm{b}}(\mathrm{mm})$ & 45.80 & 18.60 & $42.11-49.49$ \\
\hline $\operatorname{ESR}(\mathrm{mm} / \mathrm{hr})$ & 46.24 & 28.11 & $40.66-51.82$ \\
\hline DAS 28 & 5.44 & 1.44 & $5.15-5.73$ \\
\hline
\end{tabular}

a: Early Morning Stiffness, b: Visual Analog Score 
Among 100 patients, 27\% of patients had extra articular manifestations. The most common was pulmonary manifestation among them interstitial lung disease is seen in $11 \%$ of patients. There was statistical significance between the association of extra-articular manifestation and disease severity (Fisher exact test $\mathrm{p}=0.04$, Significant) (Table 4).

Other extra articular manifestations were pleural effusion (2\%) and obstructive airway disease (4\%) among pulmonary. As a neurological manifestation 4\% had peripheral neuropathy and $2 \%$ had carpel tunnel syndrome. $5 \%$ of patient had anemia as haematological manifestation. $10 \%$ of individual had rheumatoid nodule which was second common manifestation in our study and $1 \%$ had vasculitis (Table 5).

Table 2: Distribution of the severity of the disease as per the age of the patients.

\begin{tabular}{|c|c|c|c|c|}
\hline & $\begin{array}{l}\text { DAS28 } \\
\text { score }\end{array}$ & Mean & $\begin{array}{l}\text { Standard } \\
\text { deviation }\end{array}$ & $\begin{array}{l}P \\
\text { value }\end{array}$ \\
\hline \multirow{5}{*}{$\begin{array}{l}\text { Age } \\
\text { (in } \\
\text { years) }\end{array}$} & Mild & 58.50 & 15.681 & \multirow{5}{*}{$\begin{array}{l}0.733 \\
\text { (NS) }\end{array}$} \\
\hline & Moderate & 52.75 & 15.155 & \\
\hline & Severe & 52.22 & 14.404 & \\
\hline & $\begin{array}{l}\text { Not } \\
\text { applicable }\end{array}$ & 48.33 & 9.713 & \\
\hline & Total & 52.61 & 14.449 & \\
\hline
\end{tabular}

Table 3: Distribution of the severity of the disease as per the sex of the patients.

\begin{tabular}{|c|c|c|c|c|c|}
\hline \multirow[b]{2}{*}{ SEX } & \multicolumn{4}{|c|}{ DAS 28 SCORE } & \multirow{2}{*}{ P value } \\
\hline & Mild & Moderate & Severe & Not applicable & \\
\hline Female $(n=84)$ & 6 & 18 & 58 & 2 & \multirow{2}{*}{$0.266(\mathrm{NS})$} \\
\hline Male $(n=16)$ & 0 & 6 & 9 & 1 & \\
\hline
\end{tabular}

NS: statistically not significant

Table 4: Distribution of the Severity of the disease as per the Extra-articular manifestations.

\begin{tabular}{|lllll|}
\hline $\begin{array}{l}\text { Extra articular } \\
\text { manifestations }\end{array}$ & DAS 28 SCORE & moderate & severe & Not applicable \\
\hline Hematological $(n=6)$ & 0 & 1 & 5 & 0 \\
\hline Pulmonary $(n=13)$ & 2 & 3 & 7 & 1 \\
\hline Neurological $(n=4)$ & 1 & 2 & 1 & 0 \\
\hline Vasculitis $(n=1)$ & 0 & 0 & 0 & 1 \\
\hline None $(n=73)$ & 3 & 18 & 51 & 1 \\
\hline
\end{tabular}

Table 5: Distribution of extra articular manifestations of rheumatoid Arthritis.

\begin{tabular}{|ll|}
\hline Extra articular manifestation & Frequency \\
\hline Pulmonary & \\
\hline Interstitial lung disease & 11 \\
\hline Pleural effusion & 2 \\
\hline Obstructive airway disease & 4 \\
\hline Neurological & \\
\hline Peripheral neuropathy & 4 \\
\hline Carpal Tunnel Syndrome & 2 \\
\hline Anemia & 5 \\
\hline Rheumatoid nodule & 10 \\
\hline Vasculitis & 1 \\
\hline
\end{tabular}

\section{DISCUSSION}

A cross sectional study was done among 100 patients who fulfilled ACR criteria 1987, patients ranged in age from 20 to 81 years and mean age was $52.61 \mathrm{yrs}$, which is similar to other study done by Marc C Hochberg et al ${ }^{10}$ $84 \%$ patients were female and $16 \%$ were males, and average duration of RA was 5.85 yrs.
In this study $27 \%$ of patients had extra articular manifestations, which was similar to study conducted by Bharadwaj and Haroon ${ }^{11}$ which showed extra articular manifestation of $25.7 \%$ and in our study there was statistical significance between the association of extraarticular manifestations and disease severity $(P=0.040)$.

In this study most common extra articular manifestation was pulmonary and among pulmonary, interstitial lung disease (ILD) was commonest, seen in $11 \%$, which was similar to study conducted by Bharadwaj and Haroon. ${ }^{11}$ Anaemia (61\%) which was the common extra articular manifestations seen in study by Alghamdi et al, was found only in $5 \%$ of patients in our study, and it was of normocytic normochromic type.

In this study, $72 \%$ had rheumatoid factor test positive and $28 \%$ had seronegative arthritis which was similar observation seen in a study by Prevoo et $\mathrm{al}^{9}$ in which seropositive arthritis was seen in $78 \%$ of individuals. 


\section{CONCLUSIONS}

Extra-articular RA is a serious condition, which correlating well with the disease severity thus all patients with early RA should be initiated on DMARDS early and extensive investigation protocol is warranted in detecting the extra articular RA and treating it aggressively. Various clinical and biochemical parameters like ESR, CRP, DAS 28 score should be used regularly to assess the disease severity.

Funding: No funding sources

Conflict of interest: None declared

Ethical approval: The study was approved by the institutional ethics committee

\section{REFERENCES}

1. Meenan RF, Yelin EH, Nevitt M, Epstein WV. The impact of chronic disease. A sociomedical profile of rheumatoid arthritis. Arthritis Rheum. 1981;24:5449.

2. Lipsky PE. Rheumatoid Arthritis. In: Braunwald, Fauci, Kasper, Hausar, Longo, Jameson et al eds. Harrison's principles of internal medicine. $17^{\text {th }}$ ed. New york: McGraw-Hill; 2008:2083-2092.

3. Turesson C, Matterson EL. Management of extraarticular disease manifestations in rheumatoid arthritis. Curr Opin Rheumatol. 2004;16(3):206-11.

4. Malaviya AN, Kapoor SK, Singh RR, Kumar A, Pande I. Prevalence of rheumatoid arthritis in the adult Indian population. Rheum Int. 1993;13:131-4.

5. Wolfe F, Hawley DJ, Cathey MA. Clinical and health status measures over time: prognosis and outcome in rheumatoid arthritis. Rheumatol. 1991;18:1290-7.

6. Boers M. Rheumatoid arthritis. Treatment of early disease. Rheum Dis Clin North Am. 2001;27:40514.

7. American College of Rheumatology Subcommittee on Rheumatoid Arthritis Guidelines. Guidelines for the management of rheumatoid arthritis: 2002 update. Arthritis Rheum. 2002;46:328-46.

8. Arnett FC, Edworthy SM, Bloch DA, McShane DJ, Fries JF, Cooper NS et al. The American Rheumatism Association 1987 revised criteria for the classification of rheumatoid arthritis. Arthritis Rheum. 1988;31:315-24.

9. Prevoo MLL, Hof MA, Kuper HH, Leeuwen MA, Putte LBA, Riel PLCM. Modified disease activity scores that include twenty- eight- joint counts. Arthr Rheum. 1995;38:44-8.

10. Hochberg MC, Chang RW, Dwosh I, Lindsey S, Pincus T, Wolfe F. The American college of rheumatology 1991 revised criteria for classification of global functional status in rheumatoid arthritis. Arthr Rheum. 1992;35:498-502.

11. Bharadwaj A, Haroon N. Interstitial lung disease and neuropathy as predominant extra articular manifestations in patients with rheumatoid arthritis a prospective study. Med scimonit. 2005;11:492-50.

Cite this article as: Mahendrakumar K, Naufal Rizwan TA, Meenakshi S, Kannan R, Warun Kumar MR, Rajendran K. Study of extra-articular manifestations and disease severity in patients with rheumatoid arthritis. Int J Adv Med 2016;3:53-6. 